\title{
Breast Hamartoma: Clinical, Radiological, and Histopathological Evaluation
}

\author{
(1) Deniz Tazeoğlu, (1) Ahmet Dağ, (1) Bilal Arslan, (1) Mustafa Berkeşoğlu
}

Department of General Surgery, Faculty of Medicine Mersin University, Mersin, Turkey

\begin{abstract}
Objective: Breast hamartomas are rare, benign, and slow-growing breast tumors that can be definitively diagnosed by combining the results of clinical, radiological, and histopathological examination. This study aimed to evaluate the clinical, radiological, and histopathological features of hamartomas and summarize our clinical approach to hamartomas.

Materials and Methods: Patients diagnosed with breast hamartoma between 2010 and 2020 in our clinic were retrospectively analyzed. Demographic information, clinical examination, radiological findings, histopathological features, changes during follow-up, and follow-up data were obtained and analyzed.

Results: Of the 1,429 patients operated on in our clinic for benign breast diseases between January 2010 and March 2020, 39 (2.7\%) were diagnosed with breast hamartomas with histopathological examination. All patients were women with a median age of 37 (19-62) years. Most of the patients (64\%) were in the premenopausal period. Radiological examinations were conducted using mammography (66\%), breast ultrasonography (100\%), and breast magnetic resonance imaging (48\%). Biopsy was performed in 14 preoperative patients, and nine (64\%) patients were diagnosed with hamartoma. All patients were operated on; 37 patients underwent a lumpectomy, and two had a mastectomy. No patients had hamartoma recurrence during an average follow-up period of 39 months.

Conclusion: Hamartomas are similar to other benign breast pathologies. Definitive diagnosis can be achieved by combining the results of clinical, radiological, and histopathological examination. Given its similar composition to normal breast tissue, hamartoma has a low rate of malignancy. Definitive diagnosis and appropriate surgical treatment are required.
\end{abstract}

Keywords: Breast, hamartoma, diagnostic imaging, surgery

Cite this article as: Tazeoğlu D, Dağ A, Arslan B, Berkeşoğlu M. Breast Hamartoma: Clinical, Radiological, and Histopathological Evaluation.

Eur J Breast Health 2021; 17(4): 328-332.

\section{Key Points}

- Breast hamartoma is a rare, slow-growing breast lesion.

- Obtaining a definitive diagnosis with a single imaging method is challenging.

- Although hamartoma has benign histological characteristics, rare malignancies should not be overlooked.

\section{Introduction}

Pryn first identified breast hamartoma as "mastoma" in 1928 (1). Various cases have been reported as adenolipoma, fibroadenolipoma, or lipofibroadenoma (2). Breast hamartoma was first defined as "hamartoma" in 1971 by Arrigoni et al. (3) and was included in the World Health Organization classification in 1981 (2).

Different tissues such as milk ducts, lobules, adipose and fibrous tissue, smooth muscle, and hyaline cartilage are present in breast hamartoma (4). A breast hamartoma is an extremely rare, benign, and slow-growing breast lesion that occurs more commonly in women than men and in the perimenopausal period than other ages. It accounts for $0.7 \%$ of benign breast lesions in women (5). Although their size is between $2 \mathrm{~cm}$ and $5 \mathrm{~cm}$ on average, hamartomas can occasionally grow much larger (6). In most case series, the age range of patients with breast hamartomas is $13-88$, with an average of 45 years $(2,7)$.

Common clinical presentation of breast hamartomas is as a painless, mobile, palpable mass in the breast or anisomastia. However, breast hamartomas may not always be easily distinguished on physical examination because of small size and/or similarity to breast tissue ( 7,8$)$. 
Hamartoma diagnosis can be confirmed through mammography, ultrasonography (USG), magnetic resonance imaging (MRI), fineneedle aspiration biopsy (FNAB), and core biopsy.

In mammography screenings, hamartoma diagnosis incidence is reportedly $8 \%$ (2). On USG, hamartomas present different heterogeneous echo-patterns depending on the percentages of adipose and glandular components. Therefore, diagnosis is challenging (9). In cases of conflicting radiological and clinical findings, MRI can be used for differential diagnosis. In MRI, lesions are usually surrounded by a well-circumscribed smooth capsule and are denser than breast tissue (10).

Hamartoma is generally a benign disease but may rarely be present with breast malignancy $(11,12)$. An excisional biopsy is usually required to differentiate a hamartoma from other benign breast lesions, such as fibroadenoma, lipoma, and cystosarcoma phyllodes (13).

Clinical diagnosis in breast hamartomas can only be confirmed by combining physical examination, radiological imaging, and histological examination findings because of the lack of cytological and histological distinctive structural features (7).

We aimed to define the clinicopathological features of hamartomas and summarize our clinical approach to hamartoma over the 10 -year period of experience in our clinic.

\section{Materials and Methods}

Files of patients who had surgery for benign breast disease in our clinic between January 2010 and March 2020 were analyzed retrospectively. Patients who were diagnosed with breast hamartomas histopathologically, either through breast biopsy or postoperative histopathological examination were included in the study.

The patients' demographic data, medical history, reason for presentation and complaints, radiological findings, biopsy results, applied treatment method and operation method, histopathology results, and follow-up period were recorded. Radiological data were from mammography, breast USG, and breast MRI. Biopsy was used for histopathological diagnosis (fine-needle aspiration, core, radiology-assisted stereotactic marking), and the results were recorded. Treatment method (surgery, follow-up without surgery), surgery type (mastectomy, lumpectomy, and oncoplastic surgery), postoperative pathology results, and postoperative follow-up period of the patients were obtained.

Descriptive statistical evaluation was performed using the Statistical Package for Social Sciences (SPSS) for Windows, version 25.0 (IBM Inc., Chicago, IL., USA). The study was submitted to Mersin University Clinical Research Ethics Committee, and ethics committee approval (Ethics committee number: 2020/611-11) was obtained for the study.

\section{Result}

Of the 1,429 patients undergoing surgery for benign breast disease, $39(2.7 \%)$ were diagnosed with breast hamartoma. The patients were women, and the median age was 40 (21-62) years. Of the 39 patients, $25(64 \%)$ were in the premenopausal period and 14 (36\%) were in the postmenopausal period. Clinical presentations at the admittance included (self) palpable painless mobile mass in 31 (79\%) patients and newly detected mass during follow-up in eight (21\%) patients. The newly detected masses were asymptomatic. In addition, 23 (59\%) of the masses were located in the right breast, and 16 (41\%) were located in the left breast (Table 1).

Mammography imaging was not suitable because 13 patients were younger than 35 . USG was performed in seven of the patients, of whom six also underwent MRI. In four patients, hamartoma was diagnosed with mammography. All patients had USG. The remaining 26 patients were older than 37 , and they had mammography. MRI and USG were requested for 13 of the 26 patients; in the 13 other patients, USG and mammography were regarded as sufficient before the operation (Table 1).

Mammography was performed in 26 patients. According to the Breast Imaging-Reporting and Data System (BI-RADS), 13 patients were evaluated as BI-RADS II, 11 patients as BI-RADS III, and two patients BI-RADS IV. Microcalcification was detected in two (8\%) patients, asymmetric density increments in five (19\%), and nodular opacity in $14(54 \%)$.

Table 1. Demographic, clinical, radiological, surgical, and pathological data of the pçatients
Age (years)

Gender

Female

Male

Premenopausal

Postmenopausal

Laterality of lesion

Right

Left

Presenting symptoms

Painless mass

Incidental

Preoperative diagnosis

Core biopsy

Hamartoma

Fibroadenoma

Adenolipoma

Radiological modality

Ultrasonography

Mammography

Magnetic resonance imaging

Surgical technique

Lumpectomy

Mastectomy

Tumor size (mm)

n: Number n

37

2

$\%$

$40(21-62)$

39

0

25

14

23

16

59

16

79

21

36

36

64

21

15

2

39

100

26

67

49

19

95

5
$23(8-45)$ 
Breast USG findings yielded a smooth-contoured appearance in all patients, solid appearance in three patients, and heterogeneous echogenicity in 29 patients. Nineteen patients had breast MRI.

MRI findings were as follows. While 19 patients had masses with smooth borders, 13 patients had heterogeneous masses, six had pure solid masses, nine had masses with thick-walled borders, and none had masses with irregular borders or cystic structures. Hamartoma was suggested as a preliminary diagnosis in 13 (68\%) after MRI. Common characteristics of patients who required MRI were evaluated and it was found that they tended to be older than the other patients, and their mass sizes were smaller (Figure 1). Suspicious lesions were not detected in the axilla of any of the patients with radiological examinations. The success of imaging methods in detecting breast hamartoma in patients undergoing imaging was $30 \%$ in mammography, $18 \%$ in USG, and $68 \%$ in MRI.

Preoperative core biopsy was performed in 14 (35.9\%) patients but not in the remaining 25 patients. Core biopsy was the preferred biopsy type, and FNAB was not used in any patients. Biopsy results yielded the following preliminary diagnoses: hamartoma in nine patients, adenolipoma in two patients, and fibroadenoma in three patients (Table 1). The postoperative pathology result in all patients with and without biopsy was breast hamartoma. Surgery was performed in all patients because of the increase in breast size during follow-up, the high mass/breast volume ratio, or the asymmetrical appearance of the breasts.

All patients underwent surgery. Lumpectomy was performed in $37(94.9 \%)$ of the patients and simple mastectomy in two. Six of $37(16.2 \%)$ patients underwent lumpectomy using radio-guided stereotactic marking because of the small sizes of the masses. Mastectomy was preferred in two patients because of the high mass/ breast volume ratio.

Following histopathological examination, the median mass size was $23(8-45) \mathrm{mm}$. A pathology-radiology agreement was obtained for the size. The lobular structure, fibrous stromal structure, adipose tissue, smooth muscle fibers, and normal breast tissue were clustered in a scattered location within the mass lesion on histopathological examination. The mean follow-up period of the patients was 39

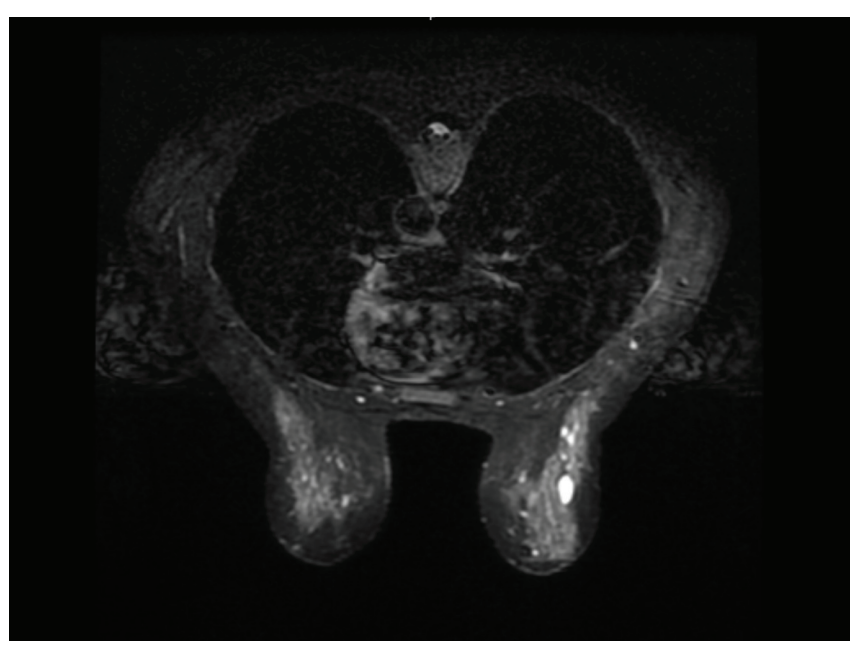

Figure 1. Minimal hyperintense lesion in the upper outer quadrant of the left breast, $11 \times 8 \mathrm{~mm}$ in size, well-circumscribed, and homogeneous, in T1W hypointense STIR months, and no recurrence or breast malignancy was detected during follow-up.

\section{Discussion and Conclusion}

Breast hamartomas are well-circumscribed, benign lesions consisting of glandular tissue, epithelial elements, fibrous tissue, and adipose tissue, which may be present in ordinary or varying proportions (14). Hamartomas are rare, slow-growing lesions with an average diameter of $2-5 \mathrm{~cm}$ but can sometimes grow to large sizes (6). They are common in middle-aged women during the perimenopausal period. Hamartomas rarely occur in ectopic breast tissue located in the axillary or inguinal region and are again rarely detected in males (15).

In situ and infiltrative carcinomas may occur inside or adjacent to hamartomas despite being histologically benign (16, 17). Given their small size, hamartomas are challenging to diagnose through a physical examination. The diagnosis is achieved with the widespread use of breast screening methods including biopsy and various imaging methods (7).

The clinical diagnosis of hamartoma is based on the combined findings of mammography, sonography, and histological analysis. Combining the diagnostic methods is much better than the use of any single method, which might lead to misdiagnosis (7).

No specific finding has been described in imaging methods. Given their difference in composition from breast tissue, hamartomas may have different radiological findings. Hamartomas are mammary lesions that can show different opacities on mammography, round or ovoid shape, and sharply limited or smooth contours; they can also be heterogeneous or easily separated from normal breast tissue (18). In the present study, four (10\%) patients had a preliminary diagnosis of hamartoma with mammography alone.

In contrast to mammography, USG can provide detailed information about the borders, nature, content, mobility, and homogeneity of the breast lesion. Although USG has relative advantages to mammography, cross-sectional examinations such as MRI are required in patients with a history of surgery and high breast volume to diagnose breast hamartoma accurately (19). A previous study reported that breast MRI was more successful than USG and mammography in the radiological diagnosis of breast hamartoma (20). The results from our study support this finding.

The characteristics of breast hamartoma on MRI examination are as follows: smooth, intense, heterogeneous appearance, and an appearance similar to adipose tissue inside. Given its crosssectional nature, breast MRI during the diagnosis and classification of hamartoma is a more advantageous imaging method than mammography and USG. It allows distinction of the mass from the normal breast tissue and accurate evaluation of the lesion's borders and structure (10). Testempassi et al. (20) evaluated the MRIs of patients diagnosed with breast hamartoma and found a correlation between the MRI findings and the macroscopic appearance of the lesion. Erdem et al. (15) employed MRI in women who were not able to undergo mammography because of breastfeeding or pregnancy and found that MRI can verify the diagnosis by providing additional information after USG. However, MRI may be inadequate in reaching a definite diagnosis of breast hamartoma in some cases. Ko et al. (21) highlighted the issue of MRI findings being similar to malignancy because of the distribution of different tissue components within the 
hamartoma, and further examination may be required to achieve a differential diagnosis.

Breast hamartomas consist of breast canals, lobules, fibrous stroma, adipose tissue, and varying amounts of smooth muscle (4). On histopathological examinations of samples taken from our cohort, all structures defined within normal breast tissue had heterogeneous distributions at varying rates.

Hamartomas contain normal breast tissue cytologically and histologically and have a heterogeneous tissue distribution. Thus, diagnosis is limited to fine-needle aspiration and core biopsy accompanied by USG. By comparison, surgical resection is more useful for identifying hamartomas and allows the examination of all tissue components (22). Surgical treatment is recommended for patients with suspicion of hamartoma or with a firm diagnosis of hamartoma (9). In our series, 14 patients were biopsied and nine (64\%) patients were diagnosed preoperatively with hamartoma, whereas five $(36 \%)$ patients were diagnosed with non-hamartoma. Previous studies reported that breast hamartomas cannot be followed up without surgery in patients with small-sized hamartomas with histopathological diagnosis $(23,24)$.

Breast hamartomas are not premalignant. However, given their glandular breast tissue, breast hamartomas can rarely undergo malignant changes similar to normal breast tissue. Therefore, achieving a definitive histopathological diagnosis is crucial. The incidence of malignancy in normal breast tissue within the hamartoma is as low as $0.1 \%$. A previous study detected lobular carcinoma in situ and invasive carcinomas by performing excisional biopsy after obtaining mammography results suggesting possible malignancy due to irregular microcalcifications and tissue changes (25).

Hamartomas are usually smooth-bordered, mobile, non-invasive lesions on the chest wall and skin. They should be removed with as minor a surgical intervention as possible. However, eradicating the lesion with a robust surgical margin is also essential because of the potential for recurrence and, rarely, possible malignancy foci within the lesion (9). Breast hamartomas may occur in masses that do not radiologically suggest a breast hamartoma and are not indicated for biopsy.

Ethics Committee Approval: The study was submitted to Mersin University Clinical Research Ethics Committee, and ethics committee approval (no: 2020/611-11) was obtained for the study.

Informed Consent: Retrospective study.

Peer-review: Externally peer-reviewed.

\section{Authorship Contributions}

Conception: D.T.; Design: A.D.; Supervision: A.D.; Materials: D.T.; Data Collection and/or Processing: B.A.; Analysis and/or Interpretation: M.B.; Literature Review: M.B.; Writing: D.T., B.A.; Critical Review: A.D.

Conflict of Interest: No conflict of interest was declared by the authors.

Financial Disclosure: The authors declared that this study received no financial support.

\section{References}

1. Pyrm P. Pseudoadenome, adenome und mastome der weiblichen brustdrüse; studien für die entstehung umschriebener adenom-ähnlicher herde in der mamma und für die nachahmung der brustdrüsengewebes durch echte adenome und fibroadenome [Article in German]. Beitr Pathol Anat Pathol 1928; 81: 221. [Crossref]

2. Wahner-Roedler DL, Sebo T, Gisvold J. Hamartomas of the breast: clinical, radiologic, and pathologic manifestations. Breast J 2001; 7: 101105. (PMID: 11328316) [Crossref]

3. Arrigoni, MG, Dockerty, MB, Judd ES. The identification and treatment of mammary hamartoma. Surg Gynecol Obstet 1971; 133: 577. (PMID: 5096305) [Crossref]

4. Turkyilmaz Z, Aydin T, Yilmaz R, Onder S, Ozkurt E, Tukenmez M, et al. Our 20-year institutional experience with surgical approach for breast hamartomas. Eur J Breast Health 2019; 15: 171-175. (PMID: 31312793) [Crossref]

5. Herbert M, Sandbank J, Liokumovich P. Breast hamartomas: clinicopathological and immunohistochemical studies of 24 cases. Histopathology 2002; 41: 30-34. (PMID: 12121234) [Crossref]

6. Sanal HT, Ersoz N, Altinel O, Unal E, Can C. Giant hamartoma of the breast. Breast J 2006; 12: 84-85. (PMID: 16409596) [Crossref]

7. Weinzweig N, Botts J, Marcus E. Giant hamartoma of the breast. Plast Reconst Surg 2001; 107: 1216-1220. (PMID: 11373565) [Crossref]

8. Puı MH, Movson IJ. Fatty tissue breast lesions. Clin Imaging 2003; 27: 150-155. (PMID: 12727050) [Crossref]

9. Ngeow J, Sesock K, Eng C. Breast cancer risk and clinical implications for germline PTEN mutation carriers. Breast Cancer Res Treat 2017; 165: 1-8. (PMID: 26700035) [Crossref]

10. Tovar JR, Callejas M, Alaez A. Infiltrating ductal carcinoma and ductal carcinoma-in-situ associated with mammary hamartoma. Breast J 2006; 12: 368-370. (PMID: 16848850) [Crossref]

11. Kemp TL, Kilgore MR, Javid SH. Invasive ductal carcinoma arising within a large mammary hamartoma. Breast J 2015; 21: 196-197. (PMID: 25613435) [Crossref]

12. Baer L, Rogers SC, Farrelly P, Tornos C, Sweeney K. The first case of HER2 + invasive ductal carcinoma arising from a breast hamartoma and literature review. J Natl Med Assoc 2017; 109: 55-59. (PMID: 28259217) [Crossref]

13. Hu H, Zhang M, Liu Y, Li XR, Liu G, Wang Z. Mammary hamartoma: is ultrasound-guided vacuum-assisted breast biopsy sufficient for its treatment? Gland Surg 2020; 9: 1278-1285. (PMID: 33224802) [Crossref]

14. Khoo JJ, Alwi RI, Abd-Rahman I. Myoid hamartoma of breast with chondroid metaplasia: a case report. Malays J Pathol 2009; 31: 77-80. (PMID: 19694319) [Crossref]

15. Erdem G, Karakas HM, Isik B, Firat AK. Advanced MRI findings in patients with breast hamartomas, Diagn Interv Radiol 2017; 17: 33-37. (PMID: 20658447) [Crossref]

16. Scally N, Campbell W, Hall S, McCusker G, Stirling WJ. Invasive ductal carcinoma arising within a breast hamartoma. Ir J Med Sci 2011; 180: 767-768. (PMID: 19662489) [Crossref]

17. Franco Uliaque C, Pardo Berdun FJ. Carcinoma in situ e invasivo dentro de un hamartoma mamario [Carcinoma in situ and invasive carcinoma within a breast hamartoma]. Radiologia 2010; 52: 487-488. (PMID: 20863538) [Crossref]

18. Farrokh D, Hashemi J, Ansaripour E. Breast hamartoma: mammographic findings. Iran J Radiol 2011; 8: 258-260. (PMID: 23329952) [Crossref]

19. Tse GM, Law BK, Ma TK, Chan AB, Pang LM, Chu WC, et al. Hamartoma of the breast: a clinicopathological review. J Clin Pathol 2002; 55: 951-954. (PMID: 12461066) [Crossref]

20. Testempassi E, Ishi C, Yamada T, Fukuda K, Tada S, Nikaido T. Case report: breast hamartoma: MR findings. Radiat Med 1995; 13: 187-189. (PMID: 8539447) [Crossref] 
21. Ko MS, Jung WS, Cha ES, Choi HJ. A rare case of recurrent myoid hamartoma mimicking malignancy: imaging appearances. Korean J Radiol 2010; 11: 683-686. (PMID: 21076595) [Crossref]

22. Guray M, Sahin AA. Benign breast diseases: classification, diagnosis, and management, Oncologist 2006; 11: 435- 449. (PMID: 16720843) [Crossref]

23. Liu G, Wang ZL, Zhang MK, He Y, Liu Y. Breast hamartoma: Ultrasound, elastosonographic, and contrast-enhanced ultrasound features. J Cancer Res Ther 2019; 15: 864-870. (PMID: 31436244) [Crossref]
24. Park YM, Kim EK, Lee JH, Ryu JH, Han SS, Choi S, et al. Palpable breast masses with probably benign morphology at sonography: can biopsy be deferred? Acta Radiologica 2008; 49: 1104-1111. (PMID: 18855166) [Crossref]

25. Silva B, Rodrigues JS, Borges US. Large mammary hamartoma of axillary supernumerary breast tissue. Breast 2006; 15: 135-136. (PMID: 15990308) [Crossref] 